\title{
BMJ Open An emerging evidence base for PET-CT in the management of childhood rhabdomyosarcoma: systematic review
}

\author{
Gill Norman, ${ }^{1}$ Debra Fayter, ${ }^{1}$ Kate Lewis-Light, ${ }^{1}$ Julia Chisholm, ${ }^{2}$ Kieran McHugh, ${ }^{3}$ \\ Daniel Levine, ${ }^{2}$ Meriel Jenney, ${ }^{4}$ Henry Mandeville, ${ }^{2}$ Suzanne Gatz, ${ }^{2}$ Bob Phillips ${ }^{1}$
}

To cite: Norman G, Fayter D, Lewis-Light $\mathrm{K}$, et al. An emerging evidence base for PET-CT in the management of childhood rhabdomyosarcoma: systematic review. BMJ Open 2015:5:e006030.

doi:10.1136/bmjopen-2014006030

- Prepublication history and additional material is available. To view please visit the journal (http://dx.doi.org/ 10.1136/bmjopen-2014006030).

Received 6 July 2014 Revised 30 October 2014 Accepted 6 November 2014

\section{CrossMark}

\footnotetext{
${ }^{1}$ Centre for Reviews and Dissemination, University of York, York, North Yorkshire, UK

${ }^{2}$ Royal Marsden Hospital,

London, UK

${ }^{3}$ Great Ormond Street Hospital, London, UK ${ }^{4}$ Children's Hospital for Wales, Cardiff, UK
}

Correspondence to Dr Gill Norman; gill.norman@manchester.ac. uk

\section{ABSTRACT}

Introduction: Rhabdomyosarcoma (RMS) management depends on risk stratification at diagnosis and treatment response. Assessment methods include CT, MRI, bone scintigraphy, histological analysis and bone marrow biopsy. Advanced functional imaging (FI) has potential to improve staging accuracy and management strategies.

Methods and analysis: We conducted a systematic review (PROSPERO 2013:CRD42013006128) of diagnostic accuracy and clinical effectiveness of $\mathrm{Fl}$ in histologically proven paediatric RMS. PRISMA guidance was followed. We searched 10 databases to November 2013. Studies with $\geq 10$ patients with RMS which compared positron emission tomography (PET), PET-CT or diffusion-weighted imaging (DWI) MRI to conventional imaging at any treatment stage were included. Study quality was assessed. Limited, heterogeneous effectiveness data required narrative synthesis, illustrated by plotting sensitivity and specificity in receiver operating curve (ROC) space.

Results: Eight studies (six PET-CT, two PET) with 272 RMS patients in total were included. No DWI-MRI studies met inclusion criteria. Pooled estimates were not calculated due to sparseness of data. Limited evidence indicated initial PET-CT results were predictive of survival. PET-CT changed management of $7 / 40$ patients. Nodal involvement PET-CT: sensitivity ranged from $80 \%$ to $100 \%$; specificity from $89 \%$ to $100 \%$. Distant metastatic involvement: PET-CT sensitivity ranged from $95 \%$ to $100 \%$; specificity from $80 \%$ to $100 \%$. Data on metastases in different sites were sparse. Limited data were found on outcome prediction by PET-CT response.

Dissemination and ethics: PET/PET-CT may increase initial staging accuracy in paediatric RMS, specifically in the detection of nodal involvement and distant metastatic spread. There is a need to further assess PET-CT for this population, ideally in a representative, unbiased and transparently selected cohort of patients.

\section{BACKGROUND}

Rhabdomyosarcoma (RMS) accounts for over $50 \%$ of sarcomas in children and young people. ${ }^{2}$ Incidence is 4.6 per million aged $<20$ years. RMS frequently presents as a softtissue mass. The commonest sites of origin
Strengths and limitations of this study

- This is the first systematic review of the use of advanced functional imaging in the management of rhabdomyosarcoma (RMS) in children and young people.

- No studies of diffusion-weighted imaging-MRI in managing rhabdomyosarcoma of sufficient quality for inclusion were identified.

- Rigorous methodology identified the limitations of the existing research supporting this use of positron emission tomography (PET)/PET-CT in the staging, prognosis development and outcome assessment of diagnosed RMS.

- Paucity of evidence prevented meta-analysis of sensitivity and specificity and contributed to considerable uncertainty around the true value of PET-CT, including whether it should be considered as an additional or a replacement diagnostic tool.

- Potential benefits of PET-CT in increasing staging accuracy were identified: specifically identification of nodal involvement and metastatic spread. Clear research recommendations for incorporation of PET-CT into future treatment trials are presented.

are head and neck, genitourinary tract, and limbs. Treatment is based on a multimodality approach including neoadjuvant chemotherapy, surgery where possible, radiotherapy and adjuvant chemotherapy. Overall outcomes have improved but remain suboptimal, with 3-year event-free survival (EFS) rates for patients with localised disease of around $60 \%$ in Europe and a corresponding overall survival (OS) of $80 \% .^{3}$ Patients who present with metastatic disease have much poorer prognoses and should be considered for novel treatment strategies. Correct staging is imperative.

Current treatment protocols rest on decisions at several points during therapy. Full initial staging employs cross-sectional imaging of the primary tumour (often with MRI); further cross-sectional imaging of the chest, abdomen and pelvis; a radiolabelled bone scan; and pelvic bone marrow biopsies. These methods are also used to assess disease 
response for treatment modification and at the end of treatment as ongoing surveillance. ${ }^{3}$ The usefulness of assessment methods is under ongoing evaluation; a recent European paediatric Soft tissue Sarcoma Group (EpSSG) analysis showed that otherwise low-risk patients are unlikely to have isolated bone metastasis; in future bone scans may be omitted for these patients. ${ }^{5}$ Current assessment methods give discordant results at postchemotherapy evaluation, highlighting the potential importance of functional imaging (FI). ${ }^{6}$

FI has been incorporated into management of other malignancies (eg, staging non-small-cell lung cancer (NSCLC) and assessing treatment response in Hodgkin's lymphoma) after extensive reviews found strong evidence for positron emission tomography (PET)-CT. ${ }^{7}$ It was found to be cost-effective for assessment of recurrent colorectal cancer, ${ }^{8}$ but was less useful than non-nuclear technologies (eg, functional MRI and nodal biopsies) in regional node evaluation in breast cancer. ${ }^{9}$ Previous systematic reviews with meta-analysis of sarcomas generally have found uncertain and heterogeneous results. ${ }^{1011}$

This is the first systematic review of FI in children and young people with RMS diagnosis. FI has potential as an additional imaging technique or replacement for current imaging modalities for initial staging and/or response assessment.

\section{OBJECTIVE}

To assess the role of FI (PET/PET-CT and diffusionweighted imaging (DWI)-MRI) in the management of RMS in childhood and adolescence and to consider its potential as a tool for improving both diagnostic (staging) and prognostic evaluation. Assessment of FI for treatment response and end of treatment evaluations were secondary aims. The review was not designed to assess the differential diagnosis of RMS in patients with suspected sarcoma.

\section{METHODS}

We undertook a systematic review of the diagnostic accuracy and clinical effectiveness of PET, PET-CT and DWI-MRI for assessment of histologically proven RMS in children and young people. The protocol was registered on PROSPERO (2013:CRD42013006128) ${ }^{12}$ and PRISMA guidance adhered to. We consulted three public patient (PPI) representatives while writing the protocol and they contributed to the selection of outcomes assessed.

We searched 10 databases (including MEDLINE, EMBASE and Cochrane Central Register of Controlled Trials) from inception to November 2013 without restrictions on publication status, date or language (see online supplementary appendix 1 for full list of databases and complete search strategies).

The following prespecified inclusion criteria were applied:

- Participants: Children and young people aged 0-24 years of age who are diagnosed with histologically proven RMS of any type. Studies with mixed tumour types will be included if outcome data for RMS patients are reported separately for at least one outcome. Studies with mixed populations of children/young people and adults were included where it was clear that a majority of patients were children/young people.

- Interventions: FI: PET $\pm \mathrm{CT}$, or DWI-MRI used at any point in the management of RMS.

- Comparator. Conventional imaging (one or more of contrast-enhanced CT or standard MRI, technetium$99 \mathrm{~m}$ bone scintigraphy).

- Primary outcome: EFS or OS at any time point.

- Secondary outcomes: Relapse rates, quality of life, adverse events or acceptability of the technology (by patient, carer or health professional), histological confirmation via lesional biopsy, or independent imaging or comparative classification of staging and risk classification of disease and treatment alteration in the light of imaging tests performed.

- Study design: Prospective and retrospective studies of any design with at least 10 patients with RMS for whom separate data are available for at least one outcome (following a protocol amendment due to lack of data; originally studies were required to include $\geq 20$ patients with RMS).

Studies were assessed for inclusion and appraised for quality by two independent reviewers. We used a tool adapted from previous Health Technology Assessment (HTA) reviews ${ }^{13}{ }^{14}$ for quality assessment of case series. We also assessed the reliability of the processes followed in carrying out PET and the degree to which accepted guidelines for the semiquantification using standardised uptake values were followed. ${ }^{15}$

Data were extracted onto a prespecified form using the package EPPI-Reviewer 4 from the UK EPPI-Centre by one researcher and checked by a second (forms were piloted by two independent researchers). A third researcher was consulted where necessary. Patient-level data were extracted to enable construction of $2 \times 2$ tables for detection of nodal involvement and distant metastases. Sensitivity and specificity of PET and conventional imaging were calculated for each study and plotted in receiver operating curve (ROC) space using the METANDI package in STATA. There were insufficient data to calculate pooled sensitivity and specificity.

At all stages of the review process, we attempted to contact study authors about uncertain, missing or incomplete data.

Owing to the limited and incomplete nature of the data reported, data at the level of individual primary, nodal or metastatic sites were summarised in a narrative synthesis. Data on survival, tumour response and treatment modification were very limited and heterogeneous so were also summarised narratively.

\section{RESULTS}

Quantity and quality of evidence

We identified 1725 unique records and assessed 300 as full-text papers. Six studies of PET-CT ${ }^{16-21}$ and two of 
$\mathrm{PET}^{22} 23$ were included; these were reported in a total of 15 publications ${ }^{16-30}$ and the most up-to-date data were used in the review (see online supplementary appendix for flow diagram). All studies had a full primary English publication; in one case, survival data were available only in abstract. $^{29}$

Seven studies included only patients with RMS; ${ }^{16-19 ~ 21-23}$ one included a minority of patients with RMS with separate data. ${ }^{20}$ Data were reported on a total of 272 patients with RMS. Two additional studies reported in abstract included $>10$ patients with RMS but were excluded as, despite author contact, we were unable to obtain separate RMS patient data. ${ }^{31}$ One study reported separate RMS data only for the subset of patients with a primary tumour in the extremities and was included because of these data. ${ }^{20}$ Three studies included one or more adults aged $\geq 25$ years; these studies were included because it was clear that the great majority of patients were children/young people; median ages were 11 and 13 in two studies ${ }^{17} 23$ and the mean age in the third was 19.8. ${ }^{19}$

No studies of DWI-MRI met inclusion criteria (even after protocol amendment from $>20$ cases to $>10$ cases); only studies that assessed it for differential diagnosis with very few RMS cases were found. ${ }^{33-39}$ These studies of DWI are discussed elsewhere. ${ }^{40} \mathrm{~A}$ full list of excluded studies is available on request.

All studies used fludeoxyglucose (fluorodeoxyglucose, $18 \mathrm{~F}$ ) as the radiopharmaceutical for PET. Most studies reported using all possible conventional imaging techniques as a comparator to PET or PET-CT (see table 2). The reference (gold) standard (as distinct from the comparison with conventional imaging) was typically a mixture of histopathology, clinical examination and follow-up.

Included studies often involved more children with unfavourable prognoses than would be expected in clinical practice: $52 \%$ of the patients in the series had an unfavourable, alveolar histology compared with 20-30\% in clinical practice. ${ }^{1}$ Histology was generally not well described and information on genetic predispositions was limited to one study which noted that no patient had a history of familial cancer syndrome. ${ }^{21}$ Where reported, large numbers of patients had stage III or IV disease compared with around $15 \%$ with stage IV disease in clinical practice. ${ }^{41}$ Several studies included higher numbers of patients with primary tumours of the extremities. Study characteristics are summarised in table 1.

All studies were opportunistic case series. Most were retrospective and did not comprise consecutive series of patients. It was often unclear how representative of the eligible population the included patients were. Details of FI procedures were often not reported. See online supplementary appendix 2 for a summary of quality assessment results. Outcome reporting was inconsistent and often incomplete. In some cases this was remedied by contacting authors.

\section{Survival and related outcomes}

Only one study ( $\mathrm{N}=41$ ) reported data on OS. ${ }^{22}$ This found that metabolic activity of the primary tumour on PET-CT had prognostic significance for survival $(p=0.007)$. Also predictive of survival were PET-CT detection of nodal involvement $(\mathrm{p}=0.016)$, PET-CT detection of metastases $(\mathrm{p}=0.002)$ and a composite outcome (PET group; $\mathrm{p}=0.002)$. Dichotomisation around the point $\mathrm{SUV}_{\max } /$ $\mathrm{SUV}_{\text {liver }}=4.6$ was also predictive $(\mathrm{p}=0.002)$. Nodal and metastatic involvement retained statistical significance in a multivariate analysis; primary tumour intensity did not.

Three studies reported data on EFS. ${ }^{17} 2229$ One $(\mathrm{N}=41)$ found similar results for EFS as for OS, with prognostic significance for primary tumour intensity $(\mathrm{p}=0.005)$, lymph node detection $(\mathrm{p}=0.008)$ and metastases detection $(\mathrm{p}=0.01)$. Dichotomisation around the point $\mathrm{SUV}_{\max } /$ $\mathrm{SUV}_{\text {liver }}=4.6 \mathrm{did}$ not predict EFS. ${ }^{22}$ Another study (N=94) reported trends towards prognostic significance for PET-CT results dichotomised by $\mathrm{SUV}_{\max }=7.0$ at initial staging $(\mathrm{p}=0.08)$ and by pre-radiotherapy (RT) PET-CTpositivity (after median 15 weeks chemotherapy; $\mathrm{p}=0.06) .{ }^{17}$ At post-RT assessment PET-CT-negative patients were significantly less likely to relapse than PET-positive individuals $(\mathrm{p}=0.02)$. The third study $(\mathrm{N}=38)$, available as an abstract, reported no prognostic significance of PET-CT at any point. ${ }^{29}$ None of these reports demonstrated an additional prognostic value of metabolic activity indices above conventional prognostic criteria.

One study reported tumour response. ${ }^{16}$ In a subset of 13 patients PET-CT was more likely than conventional imaging to show complete response to treatment; most of these patients were assessed by conventional imaging as having a partial response and 12 were in remission at follow-up.

\section{Treatment alteration}

PET-CT changed the management or treatment course of $7 / 40$ patients in studies that reported this outcome. ${ }^{162021}$

\section{Quality of life and acceptability}

There were no data on quality of life or acceptability of the technology. All three PPI representatives considered that additional scans (and their associated requirements of time, travel and additional procedures) were worthwhile if they could provide additional information to inform the treatment plan and/or prognosis.

\section{Diagnostic data}

\section{Lymph nodes}

For nodal involvement, PET-CT or PET showed sensitivity of $80 \%$ (one study) ${ }^{18}$ or $100 \%$ (three studies) ${ }^{19-21}$ and specificity of $89-100 \%$ at the patient level. This is compared to sensitivity of between $67 \%$ and $86 \%$ and specificity of $90 \%$ or $100 \%$ for conventional imaging (table 2 and figure 1). The ROC space 'cross-hairs' plots show each study's estimates of sensitivity and specificity as a marker at the point estimate, with 95\% CIs demonstrated by lines. In reading such graphs, tests with better discriminatory ability fall in the top left corner of the plot, and non-discriminatory tests fall on a $45^{\circ}$ line between the bottom left and top right. ${ }^{42}$ 


\begin{tabular}{|c|c|c|c|c|c|c|c|c|c|c|c|c|c|c|}
\hline \multirow[b]{2}{*}{ Study } & \multirow{2}{*}{$\begin{array}{l}\text { Intervention } \\
\text { [Conventional imaging methods] } \\
\text { (Reference standard) }\end{array}$} & \multirow[b]{2}{*}{$\begin{array}{l}\mathrm{N}(\% \\
\text { male) }\end{array}$} & \multirow[b]{2}{*}{$\begin{array}{l}\text { Age (years): mean/ } \\
\text { median (range) }\end{array}$} & \multicolumn{8}{|c|}{ Primary tumour location } & \multirow[b]{2}{*}{ Histology (\%) } & \multirow[b]{2}{*}{$\begin{array}{l}\text { Tumour } \\
\text { stage (\%) }\end{array}$} & \multirow{2}{*}{$\begin{array}{l}\text { Risk } \\
\text { classification } \\
(\%)\end{array}$} \\
\hline & & & & Orbit & $\begin{array}{l}\mathrm{HN} \\
\text { (nPM) }\end{array}$ & $\begin{array}{l}\mathrm{HN} \\
\text { (PM) }\end{array}$ & Trunk & Extremity & $\begin{array}{l}\mathrm{GU} \\
\text { (nBP) }\end{array}$ & $\begin{array}{l}\text { GU } \\
\text { (BP) }\end{array}$ & Other & & & \\
\hline $\begin{array}{l}\text { Baum et } a^{2} \\
\text { Germany }\end{array}$ & $\begin{array}{l}\text { PET-CT (whole body) } \\
5 \text { patients received PET only. } \\
\text { [MRI, ultrasound, contrast-enhanced CT] } \\
\text { (clinical diagnosis including CT) }\end{array}$ & $41(58)$ & $9.9^{*}(1-20)$ & 2 & 5 & 2 & 0 & 19 & 2 & 3 & 8 & $\begin{array}{l}\text { Alveolar } 24 \\
(59) \\
\text { Embryonal } 17 \\
(41)\end{array}$ & NR & $\begin{array}{l}\text { Group } 10 \\
\text { Group } 211(27) \\
\text { Group } 318(44) \\
\text { Group } 412(29)\end{array}$ \\
\hline $\begin{array}{l}\text { Dharmarajan } \\
\text { et al }{ }^{17} \\
\text { USA }\end{array}$ & $\begin{array}{l}\text { PET-CT (coverage NR) Minority had no CT } \\
\text { available. [CT] (NR) }\end{array}$ & $94(50)$ & $11 \dagger(0.2-43)$ & 5 & 3 & 34 & 19 & 21 & 3 & 9 & 0 & $\begin{array}{l}\text { Alveolar } 44 \\
\text { (47) } \\
\text { Embryonal } 49 \\
\text { (52) } \\
\text { Other } 1 \text { (1) }\end{array}$ & $\begin{array}{l}\text { Stage I } 10 \\
(11) \\
\text { Stage II } 4 \text { (4) } \\
\text { Stage III } 48 \\
\text { (51) } \\
\text { Stage IV } 32 \\
\text { (34) }\end{array}$ & $\begin{array}{l}\text { Group 1:0 } \\
\text { Group 2: } 9(10) \\
\text { Group 3:53(56) } \\
\text { Group 4:32 (34) }\end{array}$ \\
\hline $\begin{array}{l}\text { Eugene et } a l^{16} \\
\text { France }\end{array}$ & $\begin{array}{l}\text { PET-CT (whole body) } \\
\text { [Bone marrow biopsy, chest radiograph, CT, } \\
\text { MRI, bone scintigraphy] } \\
\text { (Clinical examination, histopathology, } \\
\text { follow-up, US) }\end{array}$ & $23(70)$ & $8.7 \dagger(0.75-21.6)$ & 5 & 3 & 4 & 0 & 1 & 1 & 4 & 4 & $\begin{array}{l}\text { Alveolar } 9(39) \\
\text { Embryonal } 13 \\
(61) \\
\text { Other } 1(0)\end{array}$ & NR & NR \\
\hline $\begin{array}{l}\text { Federico } \\
\text { et } a l^{18} \text { USA }\end{array}$ & $\begin{array}{l}\text { PET-CT } \\
\text { (Vertex to toes) } \\
\text { [Chest CT, CT/MRI of primary and } \\
\text { local-regional nodal basin, bone scan] } \\
\text { (Clinical assessment, histology) }\end{array}$ & $30(57)$ & $7.3+(1.3-23.5)$ & 0 & 4 & 8 & 4 & 9 & 0 & 3 & 2 & $\begin{array}{l}\text { Alveolar } 11 \\
(37) \\
\text { Embryonal } 14 \\
\text { (47) } \\
\text { Other } 5 \text { (16) }\end{array}$ & NR & Unclear \\
\hline $\begin{array}{l}\text { Klem et } a P^{3} \\
\text { USA }\end{array}$ & $\begin{array}{l}\text { PET (vertex to upper thigh, lower extremities } \\
\text { depending on tumour location and clinical } \\
\text { suspicion) } \\
\text { [CT, MRI or bone scan] } \\
\text { (Imaging, pathology, clinical findings at } \\
\text { tumour board) }\end{array}$ & $24(42)$ & $13+(1.3-56)$ & 0 & 3 & 11 & 4 & 4 & 0 & 2 & 0 & $\begin{array}{l}\text { Alveolar } 14 \\
\text { (58), } \\
\text { Embryonal } 10 \\
(42)\end{array}$ & $\begin{array}{l}\text { Stage I } 2 \text { (8) } \\
\text { Stage II } 2 \text { (8) } \\
\text { Stage III } 18 \\
\text { (75) } \\
\text { Stage IV } 5 \\
(21)\end{array}$ & $\begin{array}{l}\text { Group } 10 \\
\text { Group } 21(4) \\
\text { Group } 318(75) \\
\text { Group } 45(21)\end{array}$ \\
\hline $\begin{array}{l}\text { Ricard et a } f^{1} \\
\text { France }\end{array}$ & $\begin{array}{l}\text { PET-CT (head to upper thigh ( } 4 \text { patients had } \\
\text { scans including legs)) } \\
\text { [MRI, CT (primary), bone scintigraphy } \\
\text { (metastases)] } \\
\text { (Histopathology and clinical evaluation at } \\
\text { tumour board) }\end{array}$ & $13(92)$ & $9.6+(1.8-19.1)$ & 0 & 4 & 2 & 0 & 0 & 0 & 3 & 4 & $\begin{array}{l}\text { Alveolar } 10 \\
\text { (77), } \\
\text { Embryonal } 3 \\
(23)\end{array}$ & $\begin{array}{l}\text { Stage I } 4 \\
(31) \\
\text { Stage II } 1 \text { (8) } \\
\text { Stage III } 2 \\
\text { (15) } \\
\text { Stage IV } 6 \\
\text { (46) }\end{array}$ & NR \\
\hline $\begin{array}{l}\text { Tateishi et a }\left.\right|^{19} \\
\text { Japan }\end{array}$ & $\begin{array}{l}\text { PET-CT (head to mid-thigh (2 patients had } \\
\text { scans including legs)) } \\
\text { [Chest radiograph, whole body CT, MRI } \\
\text { (primary), bone scintigraphy] } \\
\text { (Histopathology, clinical follow-up, CSF } \\
\text { evaluation) }\end{array}$ & $35(69)$ & $19.8^{*}(3-38)$ & 1 & 0 & 18 & 8 & 8 & 0 & 0 & 0 & $\begin{array}{l}\text { Alveolar } 22 \\
\text { (63), } \\
\text { Embryonal } 12 \\
\text { (34) } \\
\text { Other } 1 \text { (3) }\end{array}$ & $\begin{array}{l}\text { Stage I: } \\
\text { initial } 3(13) \\
\text { restage } 7 \\
\text { (70) } \\
\text { Stage II: } \\
\text { initial } 21 \text { (87) } \\
\text { restage } 3 \\
\text { (30) }\end{array}$ & NR \\
\hline $\begin{array}{l}\text { Volker et afo } \\
\text { Germany }\end{array}$ & $\begin{array}{l}\text { PET (whole body) } \\
\text { [Radiography (primary), chest X-ray, CT, MRI } \\
\text { (primary and additional regions where } \\
\text { clinically indicated), US (abdominal and } \\
\text { additional regions where clinically indicated), } \\
\text { bone scintigraphy] } \\
\text { (Histopathology, clinical examination including } \\
\text { follow-up) }\end{array}$ & $46(52) \ddagger$ & $12.9^{*}(1-18) \ddagger$ & NR & & & & & & & & NR & NR & NR \\
\hline
\end{tabular}


Table 2 Summary of patient-level diagnostic data: detection of nodal and distant metastatic involvement

\begin{tabular}{|c|c|c|c|c|c|c|}
\hline \multirow[b]{2}{*}{ Study } & \multirow[b]{2}{*}{ Image } & \multirow[b]{2}{*}{$\mathbf{N}$} & \multicolumn{2}{|c|}{ Sensitivity } & \multicolumn{2}{|c|}{ Specificity } \\
\hline & & & PET & Conventional imaging & PET & Conventional imaging \\
\hline \multicolumn{7}{|l|}{ Nodal involvement } \\
\hline Federico et $a l^{18}$ & PET-CT & 30 & 0.8 & - & 1 & - \\
\hline Ricard et $a^{26}$ & PET-CT & 13 & 1 & 0.75 & 0.89 & 1 \\
\hline Tateishi et al ${ }^{19}$ & PET-CT & 35 & 1 & 0.86 & 0.95 & 0.9 \\
\hline Volker et afo & PET & $4^{*}$ & 1 & 0.67 & 1 & 1 \\
\hline \multicolumn{7}{|c|}{ Distant metastatic involvement } \\
\hline Federico et $a l^{18}$ & PET-CT & 30 & 1 & 0.17 & 0.92 & 1 \\
\hline Ricard et $a^{26}$ & PET-CT & 13 & 1 & 0.83 & 1 & 0.86 \\
\hline Tateishi et $a l^{19}$ & PET-CT & 35 & 0.95 & 0.55 & 0.8 & 0.43 \\
\hline
\end{tabular}

Nodal level data from three studies also indicated that PET-CT was able to detect more positive nodes than conventional imaging with very few false positives. ${ }^{16} 1821$ One study with fully reported data found sensitivity and specificity of $100 \%$ for PET-CT compared with $75 \%$ and $94 \%$ for conventional imaging. ${ }^{16}$ Where reported, PET-CT generated many fewer indeterminate results ( 1 vs $18 / 35$ ) and more true negatives than conventional imaging. ${ }^{18}$

\section{Distant metastases}

For detection of distant metastatic sites, PET-CT had a sensitivity of $95 \%(1 \text { study })^{19}$ or $100 \%{\text { (2 studies })^{18} 21}^{21}$ and specificity of $80-100 \%$ at the patient level. This is compared to sensitivity of between $17 \%$ and $83 \%$ and

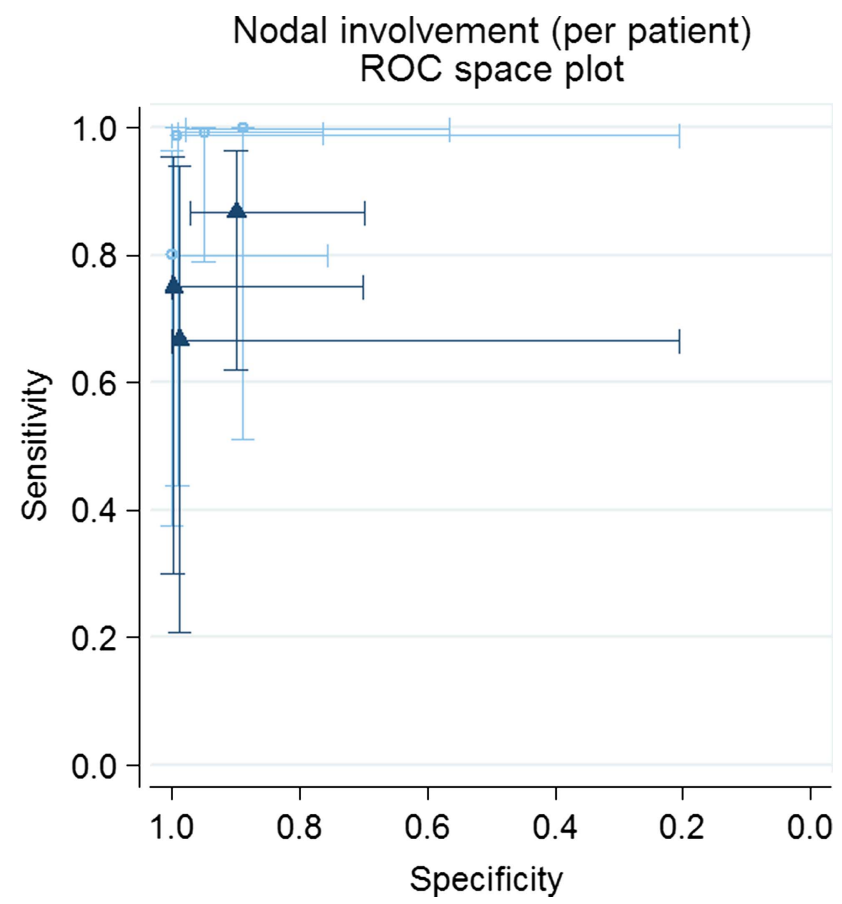

Figure 1 Sensitivity and specificity of positron emission tomography-CT versus conventional imaging in detection of nodal involvement plotted in ROC space. specificity of between $43 \%$ and $100 \%$ for conventional imaging (table 2 and figure 2).

Site level data from another study also found higher sensitivity and specificity $(100 \%$ and $96 \%)$ for PET-CT compared with $66 \%$ and $91 \%$ for conventional imaging. ${ }^{16}$

Information on detection of metastases in different sites was extremely limited and reported at the level of individual cases (table 3). ${ }^{1618} 1921$ There were indications from this very limited evidence base that PET-CT may be superior to CI for detection of bone lesions, in that both additional lesions and patients with otherwise undetectable bone involvement were identified. ${ }^{16} 181921$ The number of false positives was low. PET-CT may also have potential to specifically identify marrow involvement in some patients but this finding is unclear and based on tiny numbers of patients; sensitivity appeared limited. ${ }^{18}$ PET-CT appeared poor for detection of lung metastases. ${ }^{18} 21$ There were indications that PET-CT may perform better than conventional imaging in detecting soft-tissue lesions in non-pulmonary locations, ${ }^{18}{ }^{19}$ possibly including distal nodal involvement. ${ }^{21}$

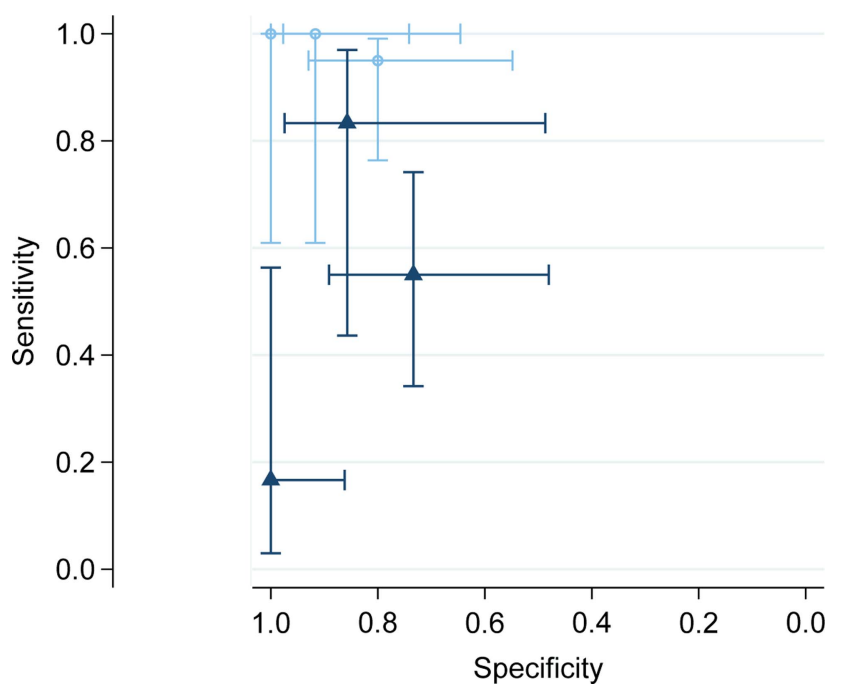

Figure 2 Sensitivity and specificity of positron emission tomography (PET)-CT versus conventional imaging in detection of distant metastatic involvement plotted in ROC space. 


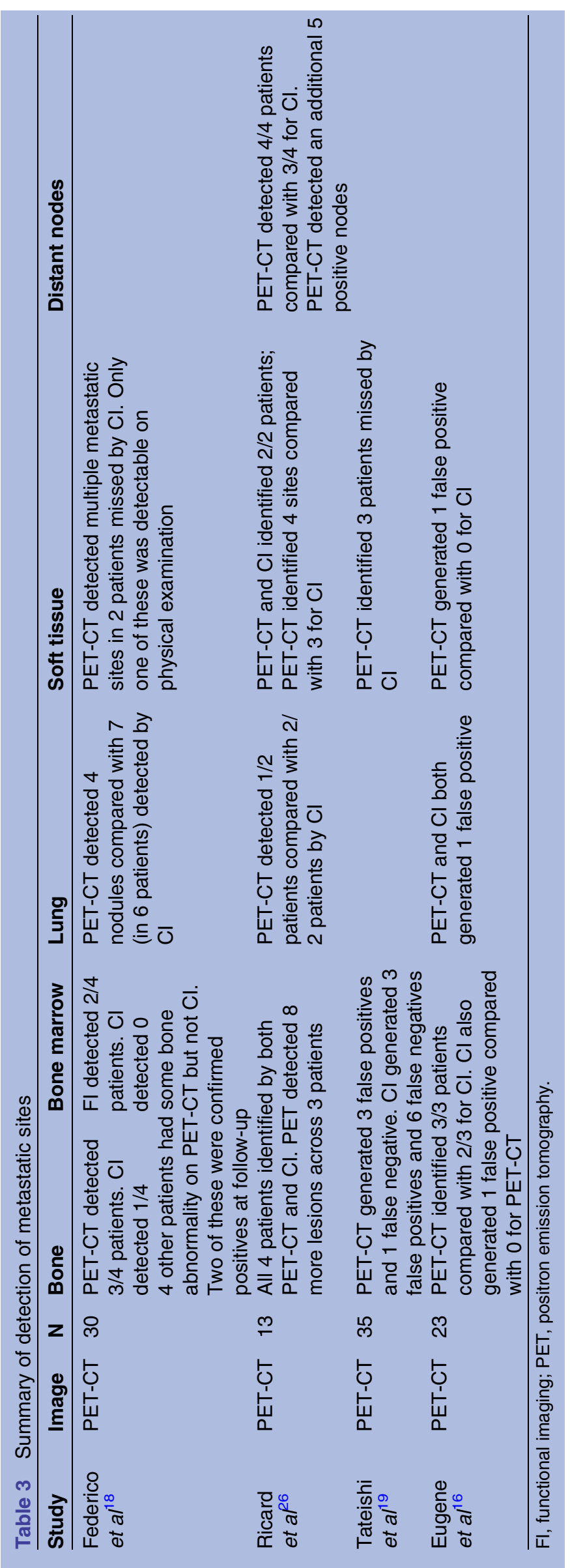

Primary tumours

The ability of PET-CT to detect primary tumours was good; only one known tumour site was missed ${ }^{16}$ and one previously occult primary was identified ${ }^{21}$; further details are in online supplementary appendix 3 .

\section{DISCUSSION}

We identified eight studies (272 patients) of PET or PET-CT in children and young people with RMS and no eligible studies of DWI-MRI.

The studies identified had multiple limitations. All studies were opportunistic case series open to a range of biases. As such they addressed multiple aspects of the use of PET in RMS management. Patients already had a diagnosis of RMS, so the studies were not diagnostic in the conventional sense; rather they were concerned with accuracy of staging, determination of prognosis and, in some cases, evaluation of treatment outcome. The review was not designed to assess the value of PET-CT in imaging primary tumours, as the requirement for histologically proven RMS diagnosis meant that almost all patients had a known tumour site. This makes comparison to earlier reviews that included all sarcomas unhelpful. ${ }^{10}$

The studies included a higher proportion of more challenging cases than expected in clinical practice. Imaging methodology was not well reported. Duplicate blinded evaluation of the FI results relative to the conventional imaging results or reference standard was often absent or unclear. Results were often not clearly or fully reported and data remained inconsistent and incomplete even after contacting authors. Our findings are therefore tentative and require confirmation by further research.

PET-CT was consistently somewhat better than conventional imaging at identifying patients with nodal involvement at initial staging and was clearly more sensitive to individual positive nodes, with fewer indeterminate results. PET-CT appeared to improve sensitivity in identification of distant metastases including identifying patients in whom distal metastatic involvement was not otherwise indicated. There is a suggestion of a role for PET-CT in detection of bone involvement but a great deal of uncertainty. Data for lung lesions are sparse and do not suggest utility. These results accord with reviews of PET-CT in staging of osteosarcoma ${ }^{43}$ and PET in general diagnosis of pulmonary nodules. ${ }^{44}$

There is very limited evidence on use of PET-CT for treatment response and end of treatment evaluation. Only three studies investigated the primary outcome of survival and one evaluated tumour response. PET-CT at initial staging may have predictive value for OS and EFS. The role of PET-CT in the assessment of treatment response before and after radiotherapy is unclear. PET-CT may be superior at ascertaining complete response to chemotherapy but this is based on one small study. The tentative findings of this review suggest that the performance of PET-CT in RMS may be closer to that in Hodgkin's lymphoma, NSCLC $^{7}$ and colorectal cancer ${ }^{8}$ than in breast cancer. ${ }^{9}$ 
None of the studies reported data on the impact of FI or conventional imaging on quality of life or acceptability to any identified stakeholder group. Our PPI representatives indicated that potential additional information was highly valued and mattered more than a need for additional procedures and the resource implications of additional scans. They were particularly supportive of FI in further research with potential to clarify possible benefits of additional or alternative imaging procedures.

This systematic review represents the first thorough evaluation of the international evidence on FI in the management of childhood and adolescent RMS. Extensive searching without language restrictions ensured the inclusion of all relevant studies. We made substantial efforts to obtain supplementary data from authors. Although some studies contained patients aged $>24$ years, we are confident from the mean/median ages reported that these were a small minority of the populations and that the relevance of the studies to the paediatric population was not significantly impacted. Excluding these studies would have resulted in the loss of data on a significant proportion of documented PET use in paediatric RMS. Studies were quality assessed and synthesised to provide an unbiased comprehensive assessment of the evidence.

The key limitation was our inability to obtain all relevant data despite contacting authors. In particular we are aware of two case series in sarcoma patients which included $>10$ patients with RMS that we could not include as authors were unable to provide separate data on RMS cases. The lack of complete patient-level data from all included studies meant we were unable to calculate pooled estimates for the sensitivity and specificity of FI and conventional imaging. However, even had we acquired full data on all known patients with paediatric RMS, the total number would have remained under 300. Any answers to the review questions would have remained tentative and uncertain. There is an urgent need for more reliable disease assessment at all stages of RMS management. PET-CT may be an option for this with sufficient prospective testing through incorporation into any future trials of RMS treatments.

\section{CONCLUSION}

This review highlights potential from PET-CT in imaging of children and adolescents with RMS but there is a high level of uncertainty in these data and their relevance to clinical practice. Limited evidence suggests that PET/ PET-CT has potential to increase initial staging accuracy, specifically detection of nodal involvement and distant metastatic spread. There is little evidence on the impact of PET-CT in assessment of therapeutic response or posttreatment assessment. The ultimate impact of FI with PET-CT on treatment outcomes could not be addressed and it remains unclear whether and how increasing accuracy at initial staging might alter patient management and survival. It was impossible to determine whether PET-CT could replace any current imaging tests or should be used as an adjunct.
DWI-MRI has been insufficiently researched to answer questions of utility in RMS; the very limited evidence base for this is discussed elsewhere. ${ }^{40}$

\section{RECOMIMENDATIONS FOR FURTHER RESEARCH}

- A representative, unbiased and transparently selected cohort of patients (entering a treatment randomised controlled trial (RCT)) should be identified. All patients should be evaluated using PET-CT as an adjunct to conventional techniques at initial staging, treatment response and end of treatment.

- The protocol should specify interim data analysis, potentially enabling PET-CT to replace one or more conventional staging techniques or substantially modify treatment delivery by response assessment.

- Results should be fully reported and individual patient data made available.

- Methodology of the PET-CT process should be standardised and reported fully. This should include independent reading of scans by multiple assessors blinded to conventional imaging and clinical/histological results.

- Appropriate qualitative methodologies should be used to assess the additional burden of treatment to patients and healthcare system, and resource use prospectively evaluated.

- Further comparative research on DWI-MRI in RMS is needed; researchers using this technology in patients with RMS should be encouraged to publish case series in the first instance.

Contributors BP designed concept for study, wrote initial draft of protocol, supervised review, undertook analysis, reviewed and edited manuscript. GN contributed to protocol, screened and assessed all papers, developed and conducted data extraction, wrote initial and edited later drafts of manuscript. DF contributed to protocol, screened and assessed all papers, developed and conducted data extraction, reviewed and edited the manuscript. KLL designed and undertook the search strategy, managed the study database and reviewed and edited the manuscript. JC, MJ, SG, DL, HM and KM contributed to the protocol, provided clinical advice to the review, reviewed and edited the manuscript.

Funding This review was funded by the Children's Cancer and Leukaemia Group (UK).

Competing interests None.

Provenance and peer review Not commissioned; externally peer reviewed.

Data sharing statement No primary data were collected for this study. Full data extractions for all included studies and a full list of excluded studies are available on request from the authors.

Open Access This is an Open Access article distributed in accordance with the Creative Commons Attribution Non Commercial (CC BY-NC 4.0) license, which permits others to distribute, remix, adapt, build upon this work noncommercially, and license their derivative works on different terms, provided the original work is properly cited and the use is non-commercial. See: http:// creativecommons.org/licenses/by-nc/4.0/

\section{REFERENCES}

1. Ries LAG, Smith MA, Gurney JG, Linet M, Tamra T, Young JL, Bunin GR, eds. Cancer incidence and survival among children and adolescents: United States SEER Program 1975-1995. NIH Pub. No. 99-4649. Bethesda, MD: National Cancer Institute, 1999. 
2. West Midlands Cancer Intelligence Unit. Soft tissue sarcomas: incidence and survival rates in England. The National Cancer Intelligence Network, 2011 (cited 04 March 2014). http://www.ncin org.uk/publications/data briefings/soft tissue sarcoma

3. Chisholm JC, Marandet J, Rey A, et al. Prognostic factors after relapse in nonmetastatic rhabdomyosarcoma: a nomogram to better define patients who can be salvaged with further therapy. $J$ Clin Oncol 2011;29:1319-25.

4. Oberlin O, Rey A, Lyden E, et al. Prognostic factors in metastatic rhabdomyosarcomas: results of a pooled analysis from United States and European cooperative groups. J Clin Oncol 2008;26:2384-9.

5. Weiss AR, Lyden ER, Anderson JR, et al. Histologic and clinical characteristics can guide staging evaluations for children and adolescents with rhabdomyosarcoma: a report from the Children's Oncology Group Soft Tissue Sarcoma Committee. J Clin Oncol 2013;31:3226-32.

6. Schoot RA, McHugh K, van Rijn RR, et al. Response assessment in pediatric rhabdomyosarcoma: can response evaluation criteria in solid tumors replace three-dimensional volume assessments? Radiology 2013;269:870-8.

7. Facey K, Bradbury I, Laking G, et al. Overview of the clinical effectiveness of positron emission tomography imaging in selected cancers. Health Technol Assess 2007:11:1-288.

8. Brush J, Boyd K, Chappell F, et al. The value of FDG positron emission tomography/computerised tomography (PET/CT) in pre-operative staging of colorectal cancer: a systematic review and economic evaluation. Health Technol Assess 2011;15:1-192.

9. Cooper KL, Meng $\mathrm{Y}$, Harnan S, et al. Positron emission tomography (PET) and magnetic resonance imaging (MRI) for the assessment of axillary lymph node metastases in early breast cancer: systematic review and economic evaluation. Health Technol Assess 2011;15: iii-iv, 1-134.

10. Bastiaannet $\mathrm{E}$, Groen $\mathrm{H}$, Jager PL, et al. The value of FDG-PET in the detection, grading and response to therapy of soft tissue and bone sarcomas: a systematic review and meta-analysis. Cancer Treat Rev 2004;30:83-101.

11. Institute for Quality and Efficiency in Health Care (Germany). Positron emission tomography (PET) in bone and soft tissue tumors (Preliminary Report). Cologne, Germany: IQWiG, 2012.

12. Fayter D, Norman G, Phillips B, et al. A systematic review of the clinical effectiveness of advanced functional imaging assessment in children and young people with rhabdomyosarcoma. PROSPERO. 2013:CRD42013006128.

13. Maund E, Craig D, Suekarran S, et al. Management of frozen shoulder: a systematic review and cost-effectiveness analysis. Health Technol Assess 2012;16:1-264.

14. Norman G, Llewellyn A, Harden M, et al. Systematic review of the limited evidence base for treatments of Eustachian tube dysfunction a health technology assessment. Clin Otolaryngol 2014;39:6-21.

15. Adams MC, Turkington TG, Wilson JM, et al. A systematic review of the factors affecting accuracy of SUV measurements. AJR Am J Roentgenol 2010;195:310-20.

16. Eugene T, Corradini N, Carlier T, et al. 18F-FDG-PET/CT in initial staging and assessment of early response to chemotherapy of pediatric rhabdomyosarcomas. Nucl Med Commun 2012;33:1089-95.

17. Dharmarajan KV, Wexler LH, Gavane S, et al. Positron emission tomography (PET) evaluation after initial chemotherapy and radiation therapy predicts local control in rhabdomyosarcoma. Int $J$ Radiat Oncol Biol Phys 2012;84:996-1002.

18. Federico SM, Wu J, Spunt SL, et al. Comparison of PET-CT and conventional imaging in staging pediatric rhabdomyosarcoma. Pediatr Blood Cancer 2012;60:1128-34.

19. Tateishi U, Hosono A, Makimoto A, et al. Comparative study of FDG $\mathrm{PET} / \mathrm{CT}$ and conventional imaging in the staging of rhabdomyosarcoma. Ann Nucl Med 2009;23:155-61.

20. Volker T, Denecke T, Steffen I, et al. Positron emission tomography for staging of pediatric sarcoma patients: results of a prospective multicenter trial. J Clin Oncol 2007;25:5435-41.

21. Ricard F, Cimarelli S, Deshayes $\mathrm{E}$, et al. Additional benefit of F-18 FDG PET/CT in the staging and follow-up of pediatric rhabdomyosarcoma. Clin Nucl Med 2011;36:672-7.
22. Baum SH, Fruhwald M, Rahbar K, et al. Contribution of PET/CT to prediction of outcome in children and young adults with rhabdomyosarcoma. J Nucl Med 2011;52:1535-40.

23. Klem ML, Grewal RK, Wexler LH, et al. PET for staging in rhabdomyosarcoma: an evaluation of PET as an adjunct to current staging tools. J Pediatr Hematol Oncol 2007;29:9-14.

24. Eugene T, Ansquer C, Oudoux A, et al. FDG PET/CT in initial staging and early response to chemotherapy assessment of paediatric rhabdomyosarcomas. Medecine Nucleaire 2010;34:655-63.

25. Dharmarajan KV, Wexler LH, Tom A, et al. Positron emission tomography (PET) response to initial chemotherapy and radiation therapy (RT) predicts local control in rhabdomyosarcoma. Int $J$ Radiat Oncol Biol Phys 2011;1:S116.

26. Ricard F, Cimarelli S, Deshayes E, et al. Utility of FDG PET/CT in childhood rhabdomyosarcoma. Eur J Nucl Med Mol Imaging 2010;37:S443

27. McCarville B, Krasin M, Spunt S, et al. PET/CT in pediatric rhabdomyosarcoma. Pediatr Radiol 2011;41:S272.

28. Tateishi U, Yamaguchi U, Seki K, et al. Bone and soft-tissue sarcoma: preoperative staging with fluorine 18 fluorodeoxyglucose PET/CT and conventional imaging. Radiology 2007;245:839-47.

29. Krasin M, Hua C, Spunt SL, et al. FDG-PET/CT prior or subsequent to radiation is a poor predictor of local outcome in patients with group III rhabdomyosarcoma. Int J Radiat Oncol Biol Phys 2011;1: S116.

30. Federico S, McCarville B, Spunt S, et al. Comparison of PET-CT and conventional imaging in staging pediatric rhabdomyosarcoma. Pediatr Blood Cancer 2012;58:1018.

31. Nguyen JQ, Davis K, Mittra ES, et al. Clinical utility of 18F FDG $\mathrm{PET} / \mathrm{CT}$ and 99mTc MDP bone scintigraphy in patients with Ewings sarcoma and other sarcomas. Clin Nucl Med 2011;36:620.

32. Dziuk M, Raciborska A, Bilska K, et al. The value of FDG PET-CT scanning in restaging of the sarcoma in children. Eur $\mathrm{J} \mathrm{Nucl} \mathrm{Med}$ Mol Imaging 2010;37:S252.

33. Abdel Razek AAK, Gaballa G, Elhawarey G, et al. Characterization of pediatric head and neck masses with diffusion-weighted MR imaging. Eur Radiol 2009;19:201-8.

34. Lope LA, Hutcheson KA, Khademian Z. Diffusion weighted imaging in the analysis of pediatric orbital tumors. J AAPOS 2009;13:e7.

35. Humphries PD, Sebire NJ, Siegel MJ, et al. Tumors in pediatric patients at diffusion-weighted MR imaging: apparent diffusion coefficient and tumor cellularity. Radiology 2007;245:848-54.

36. Kocaoglu M, Bulakbasi N, Sanal HT, et al. Pediatric abdominal masses: diagnostic accuracy of diffusion weighted MRI. Magn Reson Imaging 2010;28:629-36.

37. Neubauer H, Evangelista L, Hassold N, et al. Diffusion-weighted MRI for detection and differentiation of musculoskeletal tumorous and tumor-like lesions in pediatric patients. World $J$ Pediatr 2012;8:342-9.

38. Oka K, Yakushiji T, Sato $\mathrm{H}$, et al. Ability of diffusion-weighted imaging for the differential diagnosis between chronic expanding hematomas and malignant soft tissue tumors. J Magn Reson Imaging 2008;28:1195-200.

39. Roshdy N, Shahin M, Kishk H, et al. MRI in diagnosis of orbital masses. Curr Eye Res 2010;35:986-91.

40. Norman G, Fayter D, Lewis-Light $\mathrm{K}$, et al. Mind the gap: extent of use of diffusion-weighted MRI in children with rhabdomyosarcoma. Pediatric Radiology [Epub ahead of print Sept 2014]. doi:0.1007/ s00247-014-3120-z.

41. Hayes-Jordan A, Andrassy R. Rhabdomyosarcoma in children. Curr Opin Pediatr 2009;21:373-8.

42. Phillips B, Stewart LA, Suttona AJ. 'Cross hairs' plots for diagnostic meta-analysis. Res Synth Methods 2011;1:308-15.

43. Quartuccio N, Treglia G, Salsano M, et al. The role of Fluorine-18Fluorodeoxyglucose positron emission tomography in staging and restaging of patients with osteosarcoma. Radiol Oncol 2013;47:97-102.

44. Barger RL, Nandalur KR. Diagnostic performance of dual-time 18F-FDG PET in the diagnosis of pulmonary nodules: a meta-analysis. Acad Radiol 2012;19:153-8. 